\title{
DEMONSTRAÇÃO DOS FLUXOS DE CAIXA: Controle gerencial ou obediência normativa?
}

\author{
STATEMENT OF CASH FLOWS: \\ Management control or regulatory compliance?
}

\author{
Karine Daga \\ karinedaga@unochapeco.edu.br \\ Universidade Comunitária da Região de \\ Chapecó - UNOCHAPECÓ
}

\author{
Silvana Dalmutt Kruger \\ silvanak@unochapeco.edu.br \\ Universidade Federal de Santa Catarina - \\ UFSC / UNOCHAPECÓ
}

\author{
Sady Mazzioni \\ sady@unochapeco.edu.br \\ Universidade Regional de Blumenau - FURB \\ Universidade Comunitária da Região de Chapecó - UNOCHAPECÓ
}

\section{RESUMO}

O objetivo do estudo é verificar a utilização da Demonstração dos Fluxos de Caixa pelas empresas, considerando-a como instrumento de controle e apoio gerencial ou para atender as exigências normativas. Os procedimentos metodológicos caracterizam a pesquisa como descritiva, de levantamento e quantitativa. A coleta dos dados ocorreu por meio de questionário aplicado a 134 gestores de empresas do município de Chapecó - SC. A análise dos dados indicou que a DFC vem sendo elaborada por $72 \%$ das empresas da amostra. A utilização dessa demonstração como controle gerencial e financeiro foi indicada por $65 \%$ das empresas investigadas e $66 \%$ a consideram como um demonstrativo útil para a tomada de decisão. Das empresas que elaboram a DFC, 34\% o fazem mensalmente, $22 \%$ semanalmente e $18 \%$ quinzenalmente, sendo o método direto utilizado por $78 \%$. Os achados da pesquisa evidenciam que $63 \%$ da amostra consideram a DFC como importante, muito importante ou imprescindível no contexto do processo decisório das empresas. Porém, $29 \%$ dos respondentes consideram a DFC como demonstrativo irrelevante ao processo de gestão. Os resultados, de modo geral, demonstraram que a DFC é utilizada como forma de controle e obtenção de informações para a tomada de decisão, se distanciando da elaboração apenas para o cumprimento da obrigatoriedade fiscal.

Palavras-chave: Demonstração do fluxo de caixa. Controle gerencial. Tomada de decisão.

\begin{abstract}
The study aimed to verify the use of the Statement of Cash Flow as an instrument of control and managerial support businesses. The methodological procedures characterized as descriptive research, survey and quantitative. Data collection was conducted through questionnaires administered to 134 managers of companies Chapeco - SC. Data analysis indicated that the DFC is being developed by $72 \%$ of enterprises, especially small and medium size businesses and large corporations. Using this statement as a management and financial control was indicated by $65 \%$ of the sample and $66 \%$ regard it as a demonstrative useful for decision making. Of firms that produce the DFC, $34 \%$ do so monthly, $22 \%$ weekly and $18 \%$ fortnightly. The direct method is used by $78 \%$ of firms that produce the statement.
\end{abstract}


The research findings show the level of importance assigned to the DFC, where $63 \%$ of the sample considers it as important, very important or essential in the context of decision-making of companies. However, $29 \%$ of respondents consider the DFC statement as irrelevant to the management process. The results generally showed that the DFC is used as a means of control and obtaining information for decision making, moving away from development towards the fulfillment of the tax obligation.

Keywords: Statement of cash flow. Managerial control. Decision making.

Artigo recebido em: 01/04/2014; Aceito em: 14/11/2014

\section{INTRODUÇÃO}

Em meio à competitividade e à concorrência que envolve o ambiente mundial dos negócios, as empresas necessitam dos relatórios contábeis com informações relevantes para subsidiar o processo gerencial. Tais informações devem demonstrar a real situação da empresa, dando suporte aos gestores na realização de controles e planos eficientes, visando condições adequadas para subsidiar a tomada de decisão (CAMPOS FILHO, 1999; ZDANOWICZ, 2012).

$\mathrm{Na}$ concepção de Iudícibus et al. (2010), junto com a globalização também emergiu a necessidade de harmonizar as normas contábeis internacionalmente, a fim de suportar as modificações ocorridas no ambiente econômico. Dentre os propósitos de uma contabilidade harmonizada internacionalmente, está a de preparar reportes financeiros mais relevantes, apoiando as decisões de investimentos dos usuários. Contudo, Modro (2010) argumenta que ainda é possível verificar-se a insistência na gestão dos negócios de forma rudimentar, sem a devida análise de dados e informações disponíveis, com reflexos nos negócios.

Com o advento da Lei 11.638 de 2007, da Lei 11.941 de 2009 e o Pronunciamento Técnico CPC 03 - Demonstração dos Fluxos de Caixa, surgiu a obrigatoriedade da elaboração da Demonstração dos Fluxos de Caixa (DFC) para as sociedades por ações de capital aberto e aquelas de grande porte (faturamento anual superior a 300 milhões de Reais). O CPC PME, com as alterações da ITG 1000, exige a divulgação do demonstrativo para as pequenas e médias empresas quando o faturamento anual ultrapassar os 3,6 milhões de Reais.

A partir desses eventos, a DFC que apresentava características de informação complementar, tornou-se um demonstrativo contábil obrigatório, determinando seu nível de importância que compreende a evidenciação das entradas e saídas de caixa e seus equivalentes, bem como, a escassez e os excedentes de caixa das organizações em determinado período de tempo. A investigação de Gilio e Afonso (2013) com empresas brasileiras de capital aberto constatou que, na percepção dos pesquisados, ocorreu uma aproximação entre a Contabilidade Gerencial e a Contabilidade Financeira, em função da convergência às normas internacionais de contabilidade.

A DFC tem seu caráter também gerencial, pois permite aos gestores uma visão acerca dos fluxos de recursos que transitam pela empresa, contribuindo para a obtenção de informações necessárias para a gestão das organizações (FREZATTI, 1997; IUDÍCIBUS et al., 2010; SILVA, 2011). Estudos anteriores como os de Braga e Marques (2001); Kwok (2002); Toledo Filho, Oliveira e Spessatto (2010), Teixeira Filho et al. (2011) e Borges, Nunes e Alves (2012), evidenciam a importância da utilização da DFC como instrumento relevante para as organizações, permitindo a projeção dos fluxos de entradas e saídas de recursos

R. Cont. Ufba, Salvador-Ba, v. 9, n. 1, p. 93 - 112, jan-mar 2015 
financeiros, além da verificação da capacidade financeira da empresa de curto, médio e longo prazo.

A DFC se apresenta como um artefato importante para o gestor financeiro da empresa, permitindo verificar como suas decisões irão se refletir nos resultados e quais serão os impactos sobre o caixa. Para o Serviço Brasileiro de Apoio às Micro e Pequenas Empresas (SEBRAE, 2013), a falta de capital de giro acarreta desequilíbrio entre as entradas e saídas de recursos da empresa, constituindo-se uma das causas que comprometem o bom desempenho das organizações.

A partir deste contexto, a pesquisa pretende responder a seguinte questão-problema: Qual a finalidade da elaboração da demonstração dos fluxos de caixa pelas empresas do município de Chapecó - SC? O objetivo é verificar a utilização da demonstração dos fluxos de caixa pelas empresas do município de Chapecó - SC.

O estudo justifica-se pela importância de verificar a utilização da DFC como instrumento gerencial, além de atender as exigências de evidenciação das empresas, constatando se a utilização da DFC visa cumprir a legislação vigente (atender a Lei 11.941/2009 e a exigência do CPC 26 e CPC 03), ou se é utilizada também como instrumento de apoio ao processo decisório das organizações. A relevância do estudo reside, também, em proporcionar novas discussões acerca da utilidade da DFC, sob o argumento de que o custo associado à produção das informações contábeis só se justifica pela utilização no processo decisório.

Os relatórios financeiros fornecem informações para ajudar os atuais e potenciais investidores, credores e outros usuários, na avaliação dos recebimentos de receitas de vendas, dividendos e juros, resgate ou vencimento de títulos e empréstimos. O conjunto de demonstrações financeiras no Brasil passou a incluir a DFC, em que as "informações históricas dos fluxos de caixa são frequentemente utilizadas como indicador do montante, época de ocorrência e grau de certeza dos fluxos de caixa futuros" (CPC 09, p. 03).

$\mathrm{O}$ estudo é composto por outras quatro seções. Na seção 2 , apresentam-se os conceitos e elementos que caracterizam a utilização da DFC, além de estudos anteriores relacionados ao tema. Na seção 3 abordam-se os aspectos metodológicos, a forma de coleta e análise dos dados. A seção 4 apresenta os resultados e a análise do levantamento realizado e a seção 5 contempla as conclusões do estudo.

\section{REVISÃO DA LITERATURA}

Neste capítulo, apresentam-se os conceitos e a importância da utilização da DFC pelas empresas, tanto como instrumento de apoio, controle, planejamento e ao processo decisório relacionado à gestão das disponibilidades de recursos, quanto relacionada à obrigatoriedade da publicação. Em seguida, são apresentados estudos correlatos à temática estudada.

\subsection{Demonstração dos fluxos de caixa: estruturação e utilização}

A origem normativa da DFC ocorreu a partir de 1987 pelo Financial Accounting Standards Board (FASB), com o propósito de atender as necessidades dos investidores e das empresas que buscavam recursos no mercado financeiro (RIBEIRO, 2010). No Brasil, a DFC estava sendo utilizada como complemento das informações apresentadas pelas demonstrações contábeis por grandes empresas brasileiras constituídas sob a forma jurídica de sociedades por ações. A elaboração se baseava em parâmetros internacionais de acordo com as orientações da Comissão de Valores Mobiliários (CVM), desde a década de 1990. 
Entretanto, a partir de 2008 com a aprovação da Lei 11.638/07, a DFC tornou-se obrigatória no Brasil. Posteriormente, disciplinada pelo Comitê de Pronunciamentos Contábeis (CPC) por meio da divulgação do CPC 03, pela Deliberação da CVM n ${ }^{\circ} 547 / 2008$, pelo Conselho Federal de Contabilidade (CFC) por meio da Resolução n ${ }^{\circ} 1.125 / 2008$ e pela Lei 11.941/09. A DFC foi introduzida no Brasil em substituição a Demonstração das Origens e Aplicações de Recursos (DOAR). De acordo com Martins (1999), essa mudança ocorreu com o intuito de facilitar o entendimento dos usuários das demonstrações contábeis, pois embora a DOAR seja uma demonstração rica em informações, a DFC apresenta definições e linguagens mais acessíveis.

De acordo com o CPC 03 (2010), este pronunciamento objetiva demonstrar todas as informações ocorridas na movimentação do caixa e equivalentes de caixa relacionados à entidade por meio da apresentação da DFC, a qual passou a ser exigida para as companhias de capital aberto e fechado, estendendo-se para as companhias de grande porte.

Iudícibus et al. (2010, p. 557), definem que:

O objetivo primário da Demonstração dos Fluxos de Caixa (DFC) é prover informações relevantes sobre os pagamentos e recebimentos, em dinheiro, de uma empresa em determinado período, e com isso ajudar os usuários das demonstrações contábeis na análise da capacidade da entidade de gerar caixa e equivalentes de caixa, bem como suas necessidades para utilizar esses fluxos de caixa.

Silva (2011, p. 23) denomina a DFC como uma "representação gráfica (planilha) e cronológica de entradas (ingressos) e saídas (desembolsos) de recursos monetários, o que permite a empresa executar suas programações financeiras e operacionais, projetadas para certo período de tempo". Assim, caberá aos gestores analisarem como a empresa deverá comportar-se no período. Segundo o CPC 26, (2011, p. 32) "A informação sobre fluxos de caixa proporciona aos usuários das demonstrações contábeis uma base para avaliar a capacidade de a entidade gerar caixa e equivalentes de caixa e as necessidades da entidade utilizar esses fluxos de caixa".

De acordo com Frezatti (1997), algumas organizações vêem o fluxo de caixa como um instrumento tático, utilizado no gerenciamento e controle das operações diárias por meio de relatórios simplificados e com menor âmbito de atuação. Porém, ainda assim, importantes para o planejamento e gerenciamento. Entretanto, outras conseguem aproveitar o fluxo de caixa como um instrumento de maior alcance, utilizando-o com perspectivas estratégicas ao elaborar uma projeção mais estendida para o fluxo do caixa.

Gonçalves e Conti (2011) esclarecem que a atuação do fluxo de caixa vai depender do porte, do ramo e também das necessidades de cada instituição. Empresas que apresentam grandes oscilações tendem a trabalhar com informações de curto prazo (diário, semanal ou mensal), enquanto que empresas com maior estabilidade em suas vendas se adaptam ao fluxo de caixa projetado para períodos maiores, tais como trimestral, semestral ou anual.

Zdanowicz (2012, p. 147) argumenta que "uma vez projetado o fluxo de caixa, a direção estará apta a tomar decisões com segurança e a enfrentar possíveis dificuldades ou sobras de caixa em decorrência das sazonalidades de mercado, por exemplo". Quando a empresa realiza operações de compra, venda e investimentos, torna-se mais vulnerável às oscilações do mercado financeiro. Porém, se estiverem amparadas por informações confiáveis poderão se preparar para aproveitar melhor as oportunidades ou superar com menor ônus as dificuldades. Conforme previsto no artigo 188 da Lei $n^{\circ} 11.638 / 07$, a DFC deve apresentar "as alterações ocorridas durante o exercício no saldo de caixa e equivalentes de caixa, segregando-as em, no 
mínimo, 3 (três) fluxos: (a) das operações; (b) dos financiamentos; e (c) dos investimentos. O Quadro 1 apresenta definições para as atividades operacionais que compõem a DFC.

\begin{tabular}{|l|l|}
\multicolumn{1}{|c|}{ Quadro 1 - Atividades operacionais } \\
\hline $\begin{array}{l}\text { Fraga e Almeida } \\
(2008, \text { p. 12) }\end{array}$ & $\begin{array}{l}\text { Definições } \\
\text { Representam pagamentos e recebimentos atrelados principalmente à geração do lucro } \\
\text { operacional da sociedade. }\end{array}$ \\
\hline $\begin{array}{l}\text { CPC PME } \\
(2009, \text { p. 34) }\end{array}$ & $\begin{array}{l}\text { São as principais atividades geradoras de receita da entidade. Portanto, os fluxos de caixa } \\
\text { decorrentes das atividades operacionais geralmente derivam de transações e de outros } \\
\text { eventos e condições que entram na apuração do resultado. }\end{array}$ \\
\hline $\begin{array}{l}\text { CPC 03 } \\
(2010, \text { p. 6) }\end{array}$ & $\begin{array}{l}\text { É um indicador chave da extensão pela qual as operações da entidade têm gerado } \\
\text { suficientes fluxos de caixa para amortizar empréstimos, manter a capacidade operacional } \\
\text { da entidade, pagar dividendos e juros sobre capital próprio e fazer novos investimentos } \\
\text { sem recorrer a fontes externas de financiamento. }\end{array}$ \\
\hline $\begin{array}{l}\text { Iudícibus et } \\
(2010, \text { p. 569) }\end{array}$ & $\begin{array}{l}\text { Envolvem todas as atividades relacionadas com a produção e entrega de bens e serviços e } \\
\text { os eventos que não sejam definidos como atividades de investimento e financiamento. } \\
\text { Normalmente relacionam-se com as transações que aparecem na DRE. }\end{array}$ \\
\hline $\begin{array}{l}\text { Padoveze } \\
(2010, \text { p. 84) }\end{array}$ & $\begin{array}{l}\text { O segmento das atividades operacionais é composto em sua totalidade da acumulação } \\
\text { dos dados de recebimento e pagamento oriundos da demonstração de resultado. São os } \\
\text { gastos e receitas das atividades de industrialização e comercialização dos produtos ou } \\
\text { serviços da empresa. }\end{array}$ \\
\hline $\begin{array}{l}\text { Zdanowicz } \\
(2012, \text { p. 30) }\end{array}$ & $\begin{array}{l}\text { Compreendem as movimentações financeiras que envolvem a consecução do objeto } \\
\text { social da empresa, por exemplo, os recebimentos de vendas, pagamentos a fornecedores e } \\
\text { salários dos funcionários com os encargos sociais pertinentes. }\end{array}$ \\
\hline
\end{tabular}

Fonte: Dados da pesquisa.

Conforme apresentado no Quadro 1, as atividades operacionais estão diretamente relacionadas com as atividades primárias desenvolvidas pela empresa, as quais resultam em entradas e saídas de caixa. Conforme Iudícibus et al. (2010) algumas das principais movimentações que afetam o fluxo de caixa operacional são: recebimento de vendas e serviços à vista ou de duplicatas descontadas, recebimento de dividendos, pagamentos a fornecedores, pagamentos de impostos aos governos e pagamentos de juros, bem como, de outros recebimentos que não sejam decorrentes das atividades de investimento e financiamento.

No Quadro 2 apresentam-se as definições quanto às atividades de investimento que devem ser evidenciadas na DFC.

Quadro 2 - Atividades de investimentos

\begin{tabular}{|l|l|}
\hline \multicolumn{1}{|c|}{ Fontes } & \multicolumn{1}{c|}{ Definições } \\
\hline $\begin{array}{l}\text { Braga e } \\
\text { Almeida } \\
(2008, \text { p. 12) }\end{array}$ & $\begin{array}{l}\text { Significam pagamentos e recebimentos relacionados fundamentalmente com realizáveis a } \\
\text { longo prazo, investimentos, imobilizado, intangível, renda fixa e renda variável. }\end{array}$ \\
\hline $\begin{array}{l}\text { CPC PME } \\
(2009, \text { p. 35) }\end{array}$ & $\begin{array}{l}\text { Aquisição ou alienação de ativos de longo prazo e outros investimentos não incluídos em } \\
\text { equivalentes de caixa. }\end{array}$ \\
\hline $\begin{array}{l}\text { CPC 03 } \\
(2010, \text { p. 7) }\end{array}$ & $\begin{array}{l}\text { Somente desembolsos que resultam em ativo conhecido nas demonstrações contábeis são } \\
\text { passíveis de classificação como atividades de investimento. }\end{array}$ \\
\hline $\begin{array}{l}\text { Iudícibus et al. } \\
(2010, \text { p. 570) }\end{array}$ & $\begin{array}{l}\text { Relacionam-se normalmente com o aumento ou diminuição dos ativos de longo prazo, (não } \\
\text { circulantes) que a empresa utiliza para produzir bens e serviços. }\end{array}$ \\
\hline $\begin{array}{l}\text { Padoveze } \\
(2010, \text { p. 85) }\end{array}$ & $\begin{array}{l}\text { O segmento das atividades de investimento conduz aos dados do ativo de longo prazo, } \\
\text { enfocando o conceito do ativo como aplicações de recursos. Devem ser registrados os } \\
\text { valores de saída para pagamento de novos investimentos, bem como os valores de entrada } \\
\text { por venda de bens ativados anteriormente. }\end{array}$ \\
\hline $\begin{array}{l}\text { Zdanowicz } \\
(2012, \text { p. 30) }\end{array}$ & $\begin{array}{l}\text { particionações em outras empresas e de ativos utilizados na produção e bens ou prestação de } \\
\text { serviços ligados ao objeto social. }\end{array}$ \\
\hline
\end{tabular}

Fonte: Dados da pesquisa.

R. Cont. Ufba, Salvador-Ba, v. 9, n. 1, p. 93 - 112, jan-mar 2015 
De acordo com as definições apresentadas no Quadro 2, verifica-se que neste fluxo estão as atividades classificadas como de longo prazo, ligadas ao objetivo social da empresa. Representa as entradas e saídas de recursos atribuídos aos itens de caráter mais permanente da organização, contribuindo para produzir bens e serviços.

Quanto às atividades de financiamento, o Quadro 3 apresenta as definições.

Quadro 3 - Atividades de financiamento

\begin{tabular}{|c|c|}
\hline Fontes & Definições \\
\hline $\begin{array}{l}\text { Braga e Almeida } \\
(2008, \text { p. } 12)\end{array}$ & $\begin{array}{l}\text { Representam pagamentos e recebimentos vinculados essencialmente a passivos e } \\
\text { patrimônio líquido. }\end{array}$ \\
\hline $\begin{array}{l}\text { CPC PME } \\
(2009, \text { p. } 35)\end{array}$ & $\begin{array}{l}\text { São as atividades que resultam das alterações no tamanho e na composição do patrimônio } \\
\text { líquido e dos empréstimos da entidade. }\end{array}$ \\
\hline $\begin{array}{l}\text { CPC 03 } \\
(2010, \text { p. } 7)\end{array}$ & $\begin{array}{l}\text { A divulgação separada dos fluxos de caixa advindos das atividades de financiamento é } \\
\text { importante por ser útil na predição de exigências de fluxos futuros de caixa por parte de } \\
\text { fornecedores de capital à entidade. }\end{array}$ \\
\hline $\begin{array}{l}\text { Iudícibus et al. } \\
(2010, \text { p. } 570)\end{array}$ & Relacionam-se com os empréstimos de credores e investidores à entidade. \\
\hline $\begin{array}{l}\text { Padoveze } \\
(2010, \text { p. } 85)\end{array}$ & $\begin{array}{l}\text { O segmento das atividades de financiamento conduz aos dados do Exigível a Longo } \\
\text { Prazo e do Patrimônio Líquido, enfocando o conceito de passivo como fonte de recursos. } \\
\text { Devemos incluir também os dados dos empréstimos e financiamentos contidos no } \\
\text { passivo circulante. }\end{array}$ \\
\hline $\begin{array}{l}\text { Zdanowicz } \\
(2012, \text { p. 30) }\end{array}$ & $\begin{array}{l}\text { São todas as captações de recursos realizados junto aos sócios e seu retorno em forma de } \\
\text { recebimento de lucros, além de contratação de empréstimos, sua amortização e despesas } \\
\text { financeiras. }\end{array}$ \\
\hline
\end{tabular}

Fonte: Dados da pesquisa.

Diante do exposto pelo Quadro 3, as atividades de financiamento estão relacionadas às movimentações que afetam o Passivo e o Patrimônio Líquido da entidade por meio de empréstimos, captações de recursos e financiamentos. Conforme o CPC 03 (2010, p. 5) "a classificação por atividade proporciona informações que permitem aos usuários avaliar o impacto de tais atividades sobre a posição financeira da entidade e o montante de seu caixa e equivalentes de caixa". Ainda, o CPC 03 evidencia que a elaboração e evidenciação da DFC podem ocorrer sob dois métodos: direto e indireto.

A DFC elaborada pelo método direto, de acordo com Zdanowicz (2012, p. 31), “caracteriza-se por relacionar os elementos dos fluxos por valores brutos, menos os itens mais significativos de entradas e saídas da empresa". Para Campos Filho (1999) o método direto classifica os recebimentos e pagamentos de uma empresa de acordo com as partidas dobradas o que permite gerar as informações a partir de critérios técnicos e não recebendo, desta forma, interferência da legislação fiscal.

De acordo com Marion (2009, p. 456) o método indireto consiste em "estender a análise dos itens não circulantes - própria daquele relatório - as alterações ocorridas nos itens circulantes (passivo e ativo circulante), excluindo, logicamente, as disponibilidades, cuja variação estamos buscando demonstrar". Assim, a DFC pelo método indireto demonstra as origens e aplicações de caixa resultante das alterações ocorridas no ciclo operacional da empresa, além de permitir a avaliação do percentual de lucro que está sendo revertido em caixa, pois esse método utiliza-se como base, no lucro líquido informado na DRE.

Gonçalves e Conti (2011) afirmam que, frequentemente, observam-se situações em que as organizações divulgam em suas demonstrações de resultados, lucros bastante consideráveis, embora a sua capacidade de caixa não seja compatível com o resultado econômico apresentado, pois o lucro do período não pode ser visto como sinônimo de caixa, logo se

R. Cont. Ufba, Salvador-Ba, v. 9, n. 1, p. 93 - 112, jan-mar 2015 
justifica a utilidade da DFC no contexto do processo decisório, como instrumento de análise das origens e aplicações das fontes de recursos, quer seja oriunda das atividades operacionais, de investimentos ou financiamentos.

Neste sentido, vários fatores podem afetar os fluxos de caixa, podendo ser fatores internos ou externos, conforme o Quadro 4.

Quadro 4 - Fatores internos e externos que afetam o fluxo de caixa

\begin{tabular}{|c|c|}
\hline $\begin{array}{l}\text { FATORES } \\
\text { INTERNOS }\end{array}$ & $\begin{array}{l}\text { Aumento no prazo de vendas concedido como uma maneira de aumentar a } \\
\text { competitividade ou a participação no mercado; } \\
\text { Compras que não estão em linha com as projeções de vendas; } \\
\text { Diferenças representativas nos prazos médios de recebimento e pagamento; } \\
\text { Ciclos de produção muito longos que não estão em consonância com o prazo médio dado } \\
\text { pelos fornecedores; } \\
\text { Política salarial incompatíveis com as receitas e demais despesas operacionais } \\
\text { Pequena ocupação do ativo fixo; } \\
\text { Distribuição de lucros incompatíveis com a capacidade de geração de caixa; } \\
\text { Custos financeiros altos originários do nível de endividamento. }\end{array}$ \\
\hline $\begin{array}{l}\text { FATORES } \\
\text { EXTERNOS }\end{array}$ & $\begin{array}{l}\text { Inflação, elevação do nível de preços e taxas de juros; } \\
\text { Diminuição das vendas em decorrência de retratação do mercado; } \\
\text { Novos concorrentes; } \\
\text { Mudanças na alíquota de impostos; } \\
\text { Aumento do nível de inadimplência. }\end{array}$ \\
\hline
\end{tabular}

Fonte: Elaborado com base em SILVA (2011, p. 25).

Conforme o Quadro 4, tanto os fatores internos quanto os fatores externos merecem atenção por parte dos gestores, visando zelar pela integridade das disponibilidades dos recursos de caixa. Silva (2011) ainda destaca a necessidade da comunicação entre os gestores, de maneira a analisar e planejar quais os possíveis impactos que determinada decisão irá provocar no caixa e, consequentemente, influenciar nos interesses da empresa. A relação de influência nos fluxos de caixa existe desde a compra de mercadorias até ao recebimento das vendas de produtos ou prestação de serviços. Por isso, a DFC é considerada um instrumento de gestão, capaz de amparar os gestores no processo decisório, pois permite constatar e planejar as eventuais carências e excedentes de caixa que possam ocorrer, bem como, estabelecer medidas para sanar tais irregularidades ou necessidades de geração de recursos.

Nesta perspectiva, a investigação de Kwok (2002) com empresas de Nova Zelândia e África do Sul, evidencia que a utilização da DFC é a principal fonte de fornecimento de informações sobre os fluxos de recursos de caixa, complementadas pelo Balanço Patrimonial e pelas notas explicativas, embora a pesquisa demonstre que nem sempre as informações sobre os fluxos de caixa sejam obtidas pelos gestores diretamente na DFC. Farshadfar e Monem (2013) investigando o uso da DFC em empresas da Austrália salientam que o fluxo de caixa desagregado em seus componentes aumenta a capacidade preditiva dos fluxos de caixa futuro, evidenciando que o método direto de DFC torna-se mais relevante como suporte ao processo decisório.

Farshadfar e Monem (2013) argumentam que a existência de um forte apelo para o uso do método direto e a inerente dificuldade dos usuários externos em estimar o fluxo de caixa direto tem conduzido grupos de usuários a requerer a adoção obrigatória do método direto. No entanto, Wallace e Choudhury e Abhikari (1999) investigaram 200 empresas do Reino Unido, constatando a preferência na utilização da DFC pelo método indireto, em que apenas duas empresas utilizavam o método direto. Os autores destacam que existe uma preferência pelo método indireto quando há permissão pelas normativas contábeis de escolha entre os modelos.

R. Cont. Ufba, Salvador-Ba, v. 9, n. 1, p. 93 - 112, jan-mar 2015 
As informações contidas na DFC permitem aos gestores realizar estimativas contábeis e projeções para melhorar a relevância da informação financeira, fornecendo-lhes informação privilegiada. E embora a qualidade da informação financeira, em muitas situações esteja comprometida pela crescente dificuldade de se realizar estimativas e previsões confiáveis, estas podem refletir na utilidade e importância da DFC na previsão dos fluxos de caixa da empresa e dos seus ganhos para o processo de tomada de decisões (LEV; LI; SOUGIANNIS, 2010).

\subsection{Estudos correlatos ao tema}

Esta seção apresenta estudos com abordagens correlatas à temática investigada, apresentando as diversas formas de aplicabilidade e os resultados obtidos em relação ao uso da DFC.

O estudo de Braga e Marques (2001) avalia a liquidez das empresas por meio da análise da DFC. Com esse intuito, foram calculados e analisados os quocientes obtidos nos relatórios publicados pelas empresas Companhia Vale do Rio Doce e Centrais Elétricas de Minas Gerais S/A. Como resultado, os autores enfatizam que a DFC exerce contribuição relevante gerando informações necessárias para a continuidade das empresas, de forma a manter o nível de liquidez satisfatório, permitindo a avaliação constante do nível de endividamento e capacidade de pagamento ou investimentos.

Quintana e Saurin (2008) verificaram por meio de um estudo realizado no Estado do Rio Grande do Sul, se as sociedades anônimas de capital aberto usavam efetivamente a DFC como instrumento para a gestão financeira. Por meio de questionários, os pesquisadores concluíram que a DFC era elaborada por $52 \%$ das empresas, sendo utilizada como instrumento de gestão por uma pequena parcela das sociedades pesquisadas. A grande maioria era adepta ao fluxo de caixa diário, tendo a DFC apenas como uma ferramenta eventual no auxílio à gestão financeira.

A pesquisa de Toledo Filho, Oliveira e Spessatto (2010) verificou a utilização do fluxo de caixa como instrumento de gestão para as microempresas. Objetivando destacar quais os procedimentos adotados pelas microempresas para o uso, controle e planejamento do fluxo de caixa, os pesquisadores utilizaram questionários aplicados a uma amostra de 135 microempresas da região central de Curitiba - PR, respondidos em sua grande maioria, pelos gestores das referidas empresas. Os resultados indicaram que quanto à elaboração, acompanhamento e controle do fluxo de caixa, $78 \%$ dos investigados afirmaram ter total domínio sobre esta ferramenta e $22 \%$ declararam que não possuíam conhecimento. Em relação à importância do fluxo de caixa, $61 \%$ consideram indispensável, $6 \%$ indicaram pequena contribuição, $17 \%$ não souberam estimar e 17 não opinaram.

Gonçalves e Conti (2011) buscaram referenciar a importância da DFC como forma de planejamento e controle financeiro das micro e pequenas empresas. Por meio de um estudo de caso realizado em uma empresa atuante no setor automobilístico de vendas e prestação de serviços, foram coletados dados referentes ao faturamento mensal dos últimos dez anos, e verificaram uma variação no faturamento mensal em mais de $20 \%$. Para eles, essa variação demonstra um acentuado grau de complexidade no que diz respeito à permanência das empresas no mercado. Sendo assim, concluíram que para garantir a sobrevivência das empresas no mercado é necessário um controle financeiro adequado, tendo o fluxo de caixa realizado e prospectivo como ferramenta capaz de exercer esse controle, a partir de correções e análises presentes e futuras.

O estudo de Macedo et al. (2011) teve por finalidade demonstrar o impacto da substituição da DOAR pela DFC com enfoque sobre o value-relevance, de acordo com as novas normas vigentes. Em análise do value-relevance entre a DOAR e a DFC nos exercícios de 2005 a

R. Cont. Ufba, Salvador-Ba, v. 9, n. 1, p. 93 - 112, jan-mar 2015 
2007 das empresas não financeiras listadas na base de dados da FIPECAFI-EXAME, os autores concluíram que a DFC possui maior relevância diante do mercado de capitais do que a DOAR. Embora a DOAR possua um nível maior de informações, a DFC apresenta-se como de mais fácil entendimento, estimulando a sua utilização e demonstrando assim, uma substituição favorável para a gestão das empresas e análises pelos usuários no processo de gestão.

Teixeira Filho et al. (2011) investigaram se as empresas se adequaram às novas solicitações sobre a DFC impostas pelo CPC 03. As empresas submetidas à análise das Demonstrações Financeiras encontram-se no sitio da CVM, referentes ao período de setembro a dezembro de 2009, totalizando 48 empresas. Ao final do estudo concluíram que há ausência de homogeneidade nas apresentações da DFC, bem como, um considerável descumprimento pela maioria das empresas abordadas, quanto às exigências determinadas pelo CPC 03 em relação à classificação e divulgação das operações que compreendem o conjunto de atividades da DFC.

A pesquisa de Borges, Nunes e Alves (2012) realiza um comparativo referente à informação obtida por meio da contabilidade de caixa e a contabilidade de acréscimos. Foram coletados dados de 82 empresas listadas na CVM e também nos títulos cotados na Bolsa de Valores de Lisboa entre o período de 2005 e 2009. Tais dados foram submetidos a análises fatoriais em conjunto com análises discriminantes. Como resultado, os autores concluíram que a DFC em conjunto com as demais demonstrações financeiras, tornam-se ferramentas importantes e úteis para avaliar a situação das empresas.

\section{PROCEDIMENTOS METODOLÓGICOS}

Metodologicamente a pesquisa caracteriza-se como descritiva, com análise de dados predominantemente quantitativa, realizada a partir de levantamento, visando identificar a utilização da DFC como instrumento de apoio gerencial às empresas do Município de Chapecó-SC.

Quanto aos objetivos, a pesquisa se caracteriza como descritiva, pois busca identificar e descrever a importância atribuída pelos gestores pela utilização da DFC. Conforme Gil (1999) a pesquisa descritiva apresenta as características de determinada população ou fenômeno, utilizando técnicas padronizadas de coleta de dados como questionários e observação sistemática. Raupp e Beuren (2004, p. 81) afirmam que a "pesquisa descritiva preocupa-se em observar os fatos, registrá-los, analisá-los, classificá-los e interpretá-los, e o pesquisador não interfere neles. Assim os fenômenos do mundo físico e humano são estudados, mas não são manipulados pelo pesquisador".

Em relação à abordagem quantitativa, Richardson (1989, p. 29) argumenta que "caracteriza-se pelo emprego de quantificação tanto nas modalidades de coleta de informações, quanto no tratamento delas por meio de técnicas estatísticas". Nesta pesquisa, a coleta de dados por meio de questionário padronizado e da análise descritiva caracteriza a análise quantitativa.

A população de pesquisa configura-se como as empresas instaladas no Município de Chapecó - SC. De acordo com a Secretaria de Desenvolvimento Econômico e Turismo de Chapecó SC, em outubro de 2013 encontravam-se instaladas no município 17.037 empresas. O questionário foi enviado para 838 empresas cadastradas no banco de dados de uma empresa de consultoria e pesquisa de mercado, no decorrer dos meses de setembro, outubro e novembro de 2013. A amostra final por acessibilidade foi composta por 134 respostas, correspondente a $16 \%$ dos questionários enviados. Os questionários foram respondidos pelos gestores da área administrativa e/ou financeira das empresas investigadas.

R. Cont. Ufba, Salvador-Ba, v. 9, n. 1, p. 93 - 112, jan-mar 2015 
Conforme Lakatos e Marconi (2011), a coleta de dados é a etapa inicial do tratamento de dados e é considerada uma tarefa exaustiva, requerendo muito mais tempo e dedicação do que o previsto, além de exigir maior esforço e persistência por parte do pesquisador. Neste sentido, o instrumento utilizado foi o questionário estruturado, adaptado de Toledo Filho, Oliveira e Spessatto (2010), Quintana e Saurin (2008), contendo questões abertas e fechadas, direcionadas às empresas investigadas. Com base nos dados coletados por meio dos questionários aplicados, verificou-se a utilização da DFC pelos gestores das empresas. Os resultados encontrados foram expostos por meio de tabelas, visando contribuir com a análise dos resultados obtidos.

\section{ANÁLISE E INTERPRETAÇÃO DOS RESULTADOS}

Apresentam-se nesta seção as características das empresas da amostra e na sequência a análise quanto às características da utilização da DFC e os principais controles utilizados pelas empresas participantes da pesquisa.

\subsection{Características das empresas da amostra}

A Tabela 1 apresenta a segregação das empresas investigadas pelo número de funcionários.

Tabela 1: Número de funcionários das empresas pesquisadas

\begin{tabular}{l|c|c}
\hline Número de funcionários & Frequência absoluta & Frequência relativa \\
\hline 01 a 40 & 73 & $54 \%$ \\
41 a 80 & 13 & $10 \%$ \\
81 a 120 & 13 & $10 \%$ \\
121 a 160 & 4 & $3 \%$ \\
Acima de 160 & 31 & $23 \%$ \\
\hline Total & 134 & $100 \%$ \\
\hline
\end{tabular}

Fonte: Dados da pesquisa

A Tabela 1 demonstra que 54\% das empresas respondentes possuem entre 1 e 40 funcionários, 23\% possuem acima de 160 funcionários, $10 \%$ entre 41 e 80 funcionários. Outras $10 \%$ mantém entre 81 e 120 colaboradores e $3 \%$ possuem entre 121 a 160 funcionários.

A Tabela 2 evidencia o ramo de atividade das empresas pesquisadas.

Tabela 2: Ramo de atividade das empresas pesquisadas

\begin{tabular}{l|c|c}
\hline \multicolumn{1}{c|}{ Ramo de atividade } & Frequência Absoluta & Frequência Relativa \\
\hline Prestadora de serviços & 50 & $37 \%$ \\
Comércio & 42 & $31 \%$ \\
Indústria & 37 & $28 \%$ \\
Indústria e Comércio & 2 & $1 \%$ \\
Cooperativa & 2 & $1 \%$ \\
Instituição Financeira & 1 & $1 \%$ \\
\hline Total & 134 & $100 \%$ \\
\hline
\end{tabular}

Fonte: Dados da pesquisa

Conforme apresentado na Tabela 2, 37\% das empresas participantes da pesquisa são prestadoras de serviços, $31 \%$ atuam na área de comércio, $28 \%$ são indústrias, e apenas $1 \%$ 
afirmou realizar as atividades de industrialização e comércio, cooperativa ou instituição financeira, respectivamente.

O tempo de atuação no mercado das empresas pesquisadas é apresentado na Tabela 3.

Tabela 3: Tempo de atuação das empresas pesquisadas

\begin{tabular}{l|c|c}
\hline \multicolumn{1}{c|}{ Tempo de atuação (anos) } & Frequência Absoluta & Frequência Relativa \\
\hline 0 a 2 & 3 & $2 \%$ \\
2 a 4 & 5 & $4 \%$ \\
4 a 6 & 5 & $4 \%$ \\
6 a 8 & 8 & $6 \%$ \\
8 a 10 & 6 & $4 \%$ \\
10 a 12 & 16 & $12 \%$ \\
12 a 14 & 11 & $8 \%$ \\
Acima de 14 & 80 & $60 \%$ \\
\hline Total & 134 & $100 \%$ \\
\hline Fonte: Dados da pesquisa
\end{tabular}

A Tabela 3 demonstra que $80 \%$ das empresas respondentes atuam no mercado há mais de 10 anos, sendo que $60 \%$ delas atuam há mais de 14 anos. Sendo assim, essas empresas passaram pelo processo de transição nos procedimentos contábeis a partir da introdução da Lei 11.638/07, além de estarem em processo de adequação das normas internacionais da contabilidade e aos pronunciamentos técnicos vigentes, inclusive quanto à elaboração e divulgação da DFC.

A Tabela 4 apresenta a distribuição das empresas da amostra quanto ao faturamento anual.

Tabela 4: Faturamento anual das empresas respondentes

\begin{tabular}{l|c|c}
\hline \multicolumn{1}{c|}{ Faturamento anual (reais) } & Frequência Absoluta & Frequência Relativa \\
\hline Até R\$ 360.000,00 & 13 & $10 \%$ \\
$\mathrm{R}$ 360.001,00 a R 3.000.000,00 & 35 & $26 \%$ \\
$\mathrm{R} \$ 3.000 .0001,00$ a R \$ 300.000.000,00 & 69 & $51 \%$ \\
Acima de R 300.000.000,00 & 17 & $13 \%$ \\
\hline Total & 134 & $100 \%$ \\
\hline
\end{tabular}

Fonte: Dados da pesquisa

Com base na Tabela 4, as empresas que apresentam faturamento entre $\mathrm{R} \$ 3.000 .001,00$ (três milhões e um reais) a $\mathrm{R} \$ 300.000 .000,00$ (trezentos milhões de reais), classificam-se como pequenas e médias empresas, representando um percentual de $51 \%$ da amostrada analisada. As empresas que possuem faturamento anual de $\mathrm{R} \$ 360.001,00$ (trezentos e sessenta mil e um reais) a $\mathrm{R} \$ 3.000 .000,00$ (três milhões de reais) representam $26 \%$ da amostra. Conforme o Art. $3^{\circ}$, da Lei Complementar $n^{\circ} 123 / 06$, estas empresas são classificadas como empresas de pequeno porte.

Empresas que apresentam faturamento anual acima de $\mathrm{R} \$ 300.000 .000,00$ (trezentos milhões de reais) correspondem a $13 \%$ da amostra e são classificadas conforme a Lei 11.638/07, em seu Art. $3^{\circ}$, como sociedades de grande porte. As outras $10 \%$ da amostra apresentam um faturamento anual de até $\mathrm{R} \$ 360.000,00$ (trezentos e sessenta mil reais). De acordo com art. $3^{\circ}$, da Lei Complementar $n^{\circ} 123 / 06$, estas são classificadas como microempresas.

Os resultados indicam que a maior parcela das empresas da amostra deste estudo é classificada como pequenas e médias empresas, totalizando 69 empresas. Sob o aspecto do faturamento, 64\% das empresas da amostra estão sujeitas a publicação da DFC, evidenciando a obrigatoriedade de sua elaboração. 
Os gestores foram questionados sobre como é realizada a contabilidade das empresas pesquisadas, se há internamente uma estrutura para os registros e apuração das informações (fiscais, contábeis e gerenciais), ou se ocorre de forma terceirizada, por meio da contratação de uma empresa de serviços contábeis, a qual se responsabiliza pelos registros, apurações tributárias/fiscais e na elaboração de relatórios e demais informações obrigatórias ou complementares, cujos resultados estão apresentados na Tabela 5.

Tabela 5: Contabilidade das empresas pesquisadas

\begin{tabular}{l|c|c}
\hline \multicolumn{1}{c|}{ Contabilidade } & Frequência Absoluta & Frequência Relativa \\
\hline Terceirizada & 83 & $62 \%$ \\
Interna & 51 & $38 \%$ \\
\hline Total & 134 & $100 \%$ \\
\hline
\end{tabular}

Fonte: Dados da pesquisa

Verifica-se pelos resultados da Tabela 5, que 62\% das empresas respondentes têm sua contabilidade realizada por organizações terceirizadas, enquanto que $38 \%$ realizam sua contabilidade internamente. Estes resultados podem influenciar no uso do demonstrativo como instrumento gerencial ou simplesmente atender à exigência da normativa.

\subsection{Características quanto à utilização dos controles contábeis}

Buscou-se identificar os principais controles utilizados pelas empresas participantes da pesquisa, apresentados na Tabela 6 .

Tabela 6: Controles utilizados pelas empresas pesquisadas

\begin{tabular}{l|c|c}
\hline \multicolumn{1}{c|}{ Controles utilizados } & Frequência Absoluta & Frequência Relativa \\
\hline Contas a receber & 123 & $92 \%$ \\
Contas a pagar & 122 & $91 \%$ \\
Custos e despesas & 105 & $78 \%$ \\
Receitas & 89 & $66 \%$ \\
DFC & 87 & $65 \%$ \\
Planejamentos e orçamento & 83 & $62 \%$ \\
DRE & 82 & $61 \%$ \\
Estoques & 78 & $58 \%$ \\
Financiamentos & 71 & $53 \%$ \\
\hline Total & 134 & $100 \%$ \\
\hline
\end{tabular}

Fonte: Dados da pesquisa

Nesta questão, os respondentes puderam marcar mais de uma opção referente aos controles utilizados pelas empresas, totalizando 840 respostas. Conforme informações contidas na Tabela 6, 92\% das empresas pesquisadas utilizam controles de contas a receber, $91 \%$ utilizam controles das contas a pagar, os controles de custos e despesas são utilizados por $78 \%$ das empresas pesquisadas. $\mathrm{O}$ controle das receitas é utilizado por $66 \%$ da amostra estudada e a DFC é utilizada por $65 \%$ das empresas. O planejamento e orçamento são utilizados por $62 \%$ e a DRE por $61 \%$ das empresas. O controle dos estoques é utilizado por $58 \%$ e o controle dos financiamentos por $53 \%$ das empresas da amostra pesquisada.

Verifica-se desta forma, que os maiores percentuais se reportam aos controles de contas a pagar e a receber. Os dados indicam uma preocupação das empresas em cumprir os compromissos assumidos e de garantir o recebimento dos créditos originados pelas vendas, controles fortemente relacionados à DFC, pois envolvem entradas e saídas de caixa.

R. Cont. Ufba, Salvador-Ba, v. 9, n. 1, p. 93 - 112, jan-mar 2015 
Na Tabela 7 demonstram-se a frequência das empresas que utilizam a DFC, sendo que $72 \%$ elaboram a DFC e $28 \%$ não elaboram o demonstrativo contábil, ou seja, com base nestes dados, verifica-se que das 134 empresas que participaram da pesquisa, apenas 37 delas não elaboram a DFC.

Tabela 7: Elaboração da DFC pelas empresas pesquisadas

\begin{tabular}{l|c|c}
\hline \multicolumn{1}{c|}{ Elaboração da DFC } & Frequência absoluta & Frequência relativa \\
\hline Sim & 97 & $72 \%$ \\
Não & 37 & $28 \%$ \\
\hline Total & 134 & $100 \%$ \\
\hline
\end{tabular}

Fonte: Dados da pesquisa

Conforme a Tabela 4, 36\% da amostra pesquisada não estão obrigadas a elaboração da DFC, conforme a legislação vigente. As empresas integrantes da pesquisa obrigadas a elaboração da DFC correspondem a 64\%, essa diferença demonstra que $8 \%$ das empresas não obrigadas (11 empresas), também têm elaborado essa demonstração. Na Tabela 7 verifica-se a utilização da DFC como instrumento de controle das organizações, ou seja, das 97 das empresas que a elaboram, 87 (Tabela 6) argumentam utilizar esse demonstrativo como forma de controle financeiro e gerencial, evidenciando a importância desse demonstrativo para o gerenciamento empresarial.

A elaboração da DFC pode ser feita por meio de dois métodos: direto ou indireto. O modelo de apresentação utilizado pelas empresas pesquisadas é demonstrado na Tabela 8.

Tabela 8: Método de elaboração da DFC pelas empresas pesquisadas

\begin{tabular}{l|c|c}
\hline \multicolumn{1}{c|}{ Método de elaboração da DFC } & Frequência absoluta & Frequência Relativa \\
\hline Direto & 76 & $78 \%$ \\
Indireto & 21 & $22 \%$ \\
\hline Total & 97 & $100 \%$ \\
\hline Fonte: Dados da pesquisa &
\end{tabular}

De acordo com a Tabela $8,78 \%$ das empresas que elaboram a DFC a fazem pelo método direto e $22 \%$ elaboram pelo método indireto. Os resultados da investigação corroboram com outros achados, que indicam um maior apoio para a utilização do método direto por vários grupos de usuários, incluindo investidores, analistas financeiros, agentes de crédito, professores universitários e gestores (JONES; WIDJAJA, 1998).

Contudo, estudos como os de Wallace, Choudhury e Abhikari (1999), Clinch, Sidhu e Sin (2002), Krishnan e Largay (2000) e Orpurt e Zang (2009) constataram o uso majoritário do método indireto para a elaboração da DFC (aproximadamente 97\% a 99\% das empresas investigadas). Além disso, os três últimos estudos indicaram que os valores do fluxo de caixa direto estimados por meio do método indireto ou do balanço patrimonial e demonstração de resultados estão sujeitos a grandes erros de medição.

Quanto à periodicidade da elaboração da DFC pelas empresas respondentes, as características estão identificadas na Tabela 9.

Tabela 9: Periodicidade da elaboração da DFC pelas empresas pesquisadas

\begin{tabular}{l|c|c}
\hline Periodicidade para elaboração da DFC & Frequência absoluta & Frequência Relativa \\
\hline Diariamente & 15 & $15 \%$ \\
Semanalmente & 21 & $22 \%$ \\
Quinzenalmente & 17 & $18 \%$ \\
Mensalmente & 33 & $34 \%$ \\
Anualmente & 11 & $11 \%$ \\
\hline
\end{tabular}

R. Cont. Ufba, Salvador-Ba, v. 9, n. 1, p. 93 - 112, jan-mar 2015 


\begin{tabular}{l|c|c}
\hline Total & 97 & $100 \%$ \\
\hline Fonte: Dados da pesquisa &
\end{tabular}

Fonte: Dados da pesquisa

A Tabela 9 demonstra que 34\% das empresas pesquisadas elaboram a DFC mensalmente e $22 \%$ indicaram elaborar semanalmente. As empresas que elaboram o demonstrativo quinzenalmente correspondem a $18 \%$, enquanto que $15 \%$ da amostra pesquisada elaboram a demonstração diariamente e outros $11 \%$ elaboram apenas anualmente.

De acordo com a legislação vigente, a obrigatoriedade da elaboração e publicação da DFC é no fim do exercício social. Porém, a partir dos dados apresentados pela pesquisa, percebe-se que por apresentar informações úteis à gestão as empresas têm elaborado a DFC em períodos diferenciados do prazo legal, evidenciando a utilização da DFC como instrumento gerencial e não apenas para atender a obrigatoriedade normativa.

Muitas informações importantes para a tomada de decisão nas organizações podem ser extraídas dos demonstrativos contábeis. Nesse sentido, a pesquisa buscou identificar quais são as principais demonstrações contábeis que as empresas utilizam para a tomada de decisão, conforme apresentado na Tabela 10.

Tabela 1: Demonstrativos contábeis utilizados para a tomada de decisão pelas empresas

\begin{tabular}{l|c|c}
\hline Demonstrativos contábeis para a tomada de decisão & Frequência Absoluta & Frequência Relativa \\
\hline DRE & 99 & $74 \%$ \\
DFC & 89 & $66 \%$ \\
BP & 67 & $50 \%$ \\
Balancete & 35 & $26 \%$ \\
DLPA & 12 & $9 \%$ \\
DVA & 7 & $5 \%$ \\
DMPL & 6 & $4 \%$ \\
Nenhum & 11 & $8 \%$ \\
Não responderam & 10 & $7 \%$ \\
\hline Total & 134 & 100 \\
\hline
\end{tabular}

Fonte: Dados da pesquisa

Conforme a Tabela 10 observa-se que os demonstrativos citados como os mais utilizados pelas empresas pesquisadas são DRE, DFC e BP, com 74\%, 66\% e 50\% respectivamente. O balancete é utilizado por $26 \%$ e a DLPA é utilizada por $9 \%$ das empresas. Outros $5 \%$ da amostra, afirmam utilizar a DVA e $4 \%$ a DMPL para a tomada de decisão. Ainda, $8 \%$ dos respondentes afirmaram não utilizar nenhum demonstrativo e $7 \%$ dos participantes não responderam.

Pela questão ter sido elaborada de forma aberta, os respondentes puderam expor livremente quais os demonstrativos que dão maior suporte à tomada de decisão dentro das empresas totalizando 355 respostas. Ainda, 19 respondentes também apontaram utilizarem relatórios gerenciais elaborados internamente que representam 14\% das empresas, os quais não foram dispostos na Tabela 10 pela mesma se destinar apenas a utilização das demonstrações contábeis. Estes resultados culminam com as evidenciações de Kwok (2002), evidenciando a utilização de outros relatórios no processo decisório, como no caso do BP citado pelos gestores da amostra.

Especificadamente sobre a utilização do fluxo de caixa projetado pelas empresas pesquisadas, a Tabela 11 demonstra sua utilização na amostra investigada.

Tabela 21: Utilização do fluxo de caixa projetado pelas empresas pesquisadas

\begin{tabular}{l|c|c}
\hline Utilização do fluxo de caixa projetado & Frequência Absoluta & Frequência Relativa \\
\hline Sim & 85 & $63 \%$
\end{tabular}

R. Cont. Ufba, Salvador-Ba, v. 9, n. 1, p. 93 - 112, jan-mar 2015 


\begin{tabular}{l|c|c} 
Não & 49 & $37 \%$ \\
\hline Total & 134 & $100 \%$ \\
\hline Fote: &
\end{tabular}

Fonte: Dados da pesquisa

Conforme a Tabela 11 verifica-se que $63 \%$ das empresas investigadas realizam a projeção do fluxo de caixa e $37 \%$ não realizam. Observa-se que, de fato, uma parcela importante das empresas utiliza a DFC como um instrumento de apoio gerencial e não apenas para cumprimento da legislação em vigor.

Na Tabela 12 apresenta-se a periodicidade para a projeção de caixa feita pelas empresas que responderam utilizar o fluxo de caixa projetado.

Tabela 12: Periodicidade da elaboração do fluxo de caixa projetado pelas empresas pesquisadas

\begin{tabular}{l|c|c}
\hline \multicolumn{1}{c}{ Projeção do fluxo de caixa (tempo) } & Frequência absoluta & Frequência Relativa \\
\hline Uma semana & 8 & $9 \%$ \\
Uma quinzena & 4 & $5 \%$ \\
28 dias & 1 & $1 \%$ \\
Um mês & 28 & $33 \%$ \\
45 dias & 1 & $1 \%$ \\
Um trimestre & 11 & $13 \%$ \\
Um semestre & 10 & $12 \%$ \\
Um ano & 19 & $22 \%$ \\
Mais de um ano & 3 & $4 \%$ \\
\hline Total & 85 & $100 \%$ \\
\hline
\end{tabular}

Fonte: Dados da pesquisa

Observa-se na Tabela 12 que 33\% das empresas realizam a projeção do fluxo de caixa para um mês, $22 \%$ para um ano e $13 \%$ elaboram por trimestre. Empresas que projetam seu fluxo de caixa por um semestre representam $12 \%$ e outras $9 \%$ das empresas elaboram de forma semanal, $5 \%$ quinzenal, $4 \%$ projetam para mais de um ano e apenas $1 \%$ indicaram que utilizam para 28 dias e 45 dias.

Conforme apresenta a Tabela 12, verifica-se que a elaboração da DFC, assim como a projeção dos fluxos de caixa, apresenta maior percentual para a opção mensal, ou seja, sua projeção contempla o prazo de 30 dias. A elevada utilização do fluxo de caixa projetado reforça a percepção de sua relevância para a análise de investimentos e para avaliação das empresas (KRISHNAN; LARGAY, 2000).

O estudo também buscou identificar qual é o nível de importância atribuído a DFC pelas empresas. A Tabela 13 demonstra a importância conferida à DFC pelas empresas pesquisadas.

Tabela 13: Importância atribuída a DFC pelas empresas pesquisadas

\begin{tabular}{l|c|c}
\hline \multicolumn{1}{c|}{ Importância da DFC } & Frequência Absoluta & Frequência Relativa \\
\hline Irrelevante & 39 & $29 \%$ \\
Eventualmente importante & 11 & $8 \%$ \\
Importante & 18 & $13 \%$ \\
Muito importante & 37 & $28 \%$ \\
Imprescindível & 29 & $22 \%$ \\
\hline Total & 134 & $100 \%$ \\
\hline
\end{tabular}

Fonte: Dados da pesquisa

Com base na Tabela 13, verificou-se que $29 \%$ das empresas pesquisadas avaliam a DFC como um demonstrativo "irrelevante" para a tomada de decisão na sua entidade. Entretanto, outros $28 \%$ consideram a DFC como um demonstrativo "muito importante" e $22 \%$ dos respondentes apontam como "imprescindível" para sua empresa. Ainda, para 13\% dos respondentes a DFC é considerada "importante" e apenas $8 \%$ a consideram como "eventualmente importante".

R. Cont. Ufba, Salvador-Ba, v. 9, n. 1, p. 93 - 112, jan-mar 2015 
Neste sentido, percebe-se que a maioria da amostra pesquisada considera relevante a utilização da DFC no processo decisório em suas organizações, estes resultados corroboram e fortalecem evidenciações de pesquisas anteriores, como as de Kwok (2002), Toledo Filho, Oliveira e Spessatto (2010), Teixeira Filho et al. (2011) e Borges, Nunes e Alves (2012), sobre a utilização da DFC.

Os respondentes também foram questionados quanto ao motivo pelo qual consideram a utilização da DFC importante para suas empresas, cujos resultados são demonstrados na Tabela 14.

Tabela 14: Motivos apontados quanto à importância da DFC para as empresas pesquisadas

\begin{tabular}{l|c|c}
\hline \multicolumn{1}{c|}{ Motivos atribuídos à importância da DFC } & Frequência absoluta & Frequência relativa \\
\hline Controle, planejamento e gestão & 20 & $29 \%$ \\
Tomada de decisões & 16 & $23 \%$ \\
Acompanhar a situação financeira & 14 & $20 \%$ \\
Acompanhar a entrada e saídas de recursos do caixa & 10 & $14 \%$ \\
Necessidade/capacidade de investimentos/financiamentos & 9 & $13 \%$ \\
\hline Total & 69 & $100 \%$ \\
\hline
\end{tabular}

Fonte: Dados da pesquisa

Verificou-se de modo geral, conforme a Tabela 14, que as empresas atribuem relevância à DFC por motivos similares. Das 69 empresas que justificaram a importância da DFC em seu processo decisório, $29 \%$ delas destacaram a capacidade de fornecer informações para o controle e planejamento das atividades da empresa, influenciando no gerenciamento da organização. Outras $23 \%$ evidenciam que a DFC é importante para a tomada de decisões, contribuindo para alcançar as metas e objetivos propostos.

Já o acompanhamento da situação financeira das empresas foi indicado como fator importante para $20 \%$ das empresas, as quais utilizam a DFC como instrumento de avaliação e verificação das reais condições financeiras que a empresa possui em determinado período de tempo. Ainda, 14\% dos respondentes apontaram a DFC como importante para a empresa, devido à possibilidade de acompanhar o fluxo de entradas e saídas de recursos do caixa, permitindo uma avaliação do capital de giro que a mesma possui. Verificou-se também que outros $13 \%$ das empresas atribuem certo nível de importância para esse demonstrativo por contribuir para a verificação da capacidade que a empresa possui em realizar investimentos ou a necessidade de captar recursos de terceiros por meio de financiamentos.

Em relação aos achados da pesquisa, a mesma corroborou os estudos de Toledo Filho, Oliveira e Spessatto (2010) no sentido de que a DFC está sendo pouco utilizada pelas microempresas e empresas brasileiras de pequeno porte como instrumento de gestão. De certa forma os resultados também indicam que $29 \%$ das empresas consideram a DFC irrelevante quanto à sua função e utilidade, sendo que $28 \%$ afirmaram não elaborar esse demonstrativo.

Entretanto, os resultados da pesquisa opõem-se parcialmente ao estudo de Quintana e Saurin (2008), que verificaram a utilização da DFC por uma minoria das sociedades anônimas de capital aberto como apenas uma ferramenta "auxiliar" para a tomada de decisão, na qual o fluxo de caixa diário é o principal instrumento de gestão nas empresas pesquisadas. Neste sentido, os resultados deste estudo apontam que 64\% das empresas da amostra estudada utilizam a DFC como instrumento gerencial. A elaboração diária ocorre em apenas $15 \%$ das empresas, onde foram apresentados também de forma semanal, quinzenal ou mensal.

Os resultados dos estudos de Braga e Marques (2001) e Borges, Nunes e Alves (2012) também se coadunam com a pesquisa realizada, tratando a DFC como instrumento relevante nas organizações, permitindo a projeção dos fluxos de entrada e saída, além da verificação da capacidade financeira da empresa.

R. Cont. Ufba, Salvador-Ba, v. 9, n. 1, p. 93 - 112, jan-mar 2015 
Dessa forma, os resultados gerais demonstram que a DFC tem apresentado uma aderência relevante pelas empresas pesquisadas, evidenciando a utilização desse demonstrativo no processo de gerenciamento das empresas como forma de controle e planejamento e não apenas como demonstração contábil obrigatória.

\section{CONCLUSÕES}

Nos últimos anos, a contabilidade brasileira passou por um processo de inovações e alterações que visam à harmonização dos seus métodos às normas internacionais da contabilidade. Dentre estas mudanças, as novas normas contábeis trouxeram a obrigatoriedade de elaboração da DFC para grande parte das empresas brasileiras por meio da Lei 11.638/07; do CPC 03 e CPC 26. Neste sentido, o estudo teve como objetivo principal verificar a utilização da demonstração dos fluxos de caixa pelas empresas do município de Chapecó - SC.

Quanto às principais características apresentadas pela pesquisa, observou-se que a periodicidade de elaboração mensal da DFC corresponde a $34 \%$ da amostra, sendo a periodicidade mais utilizada pelas 97 empresas que elaboram essa demonstração. Contudo, muitas empresas ainda demonstraram elaborar a DFC diariamente, semanalmente, quinzenalmente ou anualmente. Observa-se dessa forma, que as empresas não estão elaborando a DFC apenas para cumprir a obrigatoriedade prevista pela legislação, mas também como forma de obter informações sobre entradas e saídas de recursos regularmente, as quais contribuem para o gerenciamento das organizações.

$\mathrm{O}$ estudo identificou os controles gerenciais e financeiros utilizados pelas empresas, e por meio dos questionários aplicados verificou-se que os controles de contas a pagar, contas a receber, controle de custos e despesas e o controle de receitas são utilizados por um percentual maior de empresas. No entanto, a DFC apresentou ser utilizada por $65 \%$ das empresas, onde das 97 que a elaboram 87 utilizam a demonstração como controle. Neste sentido, a pesquisa demonstra que a DFC contribuiu na gestão das empresas pesquisadas, sendo utilizada para controlar os recursos disponíveis na empresa. Os instrumentos de controles relacionados ao planejamento e orçamento, a DRE, o controle dos estoques e de financiamentos também foi apontado pelas empresas, porém em menor quantidade de empresas da amostra.

Os achados da pesquisa evidenciam que $72 \%$ das empresas que elaboram a DFC atribuem importância para essa demonstração no processo decisório, considerando vários fatores, principalmente para o acompanhamento das entradas e saídas do caixa, da verificação da situação financeira, bem como, da necessidade e capacidade de realizar investimentos ou financiamentos, além de contribuir para o planejamento.

De modo geral, os resultados evidenciaram que embora a DFC ainda não esteja presente em todas as empresas investigadas, tem sido utilizada por uma parcela relevante das organizações. Sendo assim, pode-se concluir que a DFC tem obtido espaço e importância nas empresas, sendo tratada como um instrumento útil para a gestão e não apenas como mais uma demonstração financeira elaborada para cumprir com as obrigações da legislação vigente, mas tem sido utilizada como demonstrativo de apoio e controle ao processo decisório, principalmente quando se observa sua utilização para o acompanhamento de projeções e planejamento das necessidades de caixa, sendo utilizada gerencialmente (semanal, quinzenal, mensal, etc.).

No desenvolvimento desta pesquisa, observou-se a perspectiva de novos estudos sobre o tema, possibilitando o aprofundamento de novas abordagens. Sendo assim, como sugestões para futuros trabalhos, recomenda-se o aumento da amostra para realizar a confirmação dos

R. Cont. Ufba, Salvador-Ba, v. 9, n. 1, p. 93 - 112, jan-mar 2015 
resultados obtidos nesta pesquisa, bem como, sugere-se a realização de uma pesquisa específica junto às microempresas e empresas de pequeno porte inseridas no contexto da ITG 1000, acerca do controle do fluxo de caixa para uso gerencial, tendo em vista que a DFC não é demonstrativo obrigatório para este grupo de empresas.

\section{REFERÊNCIAS}

BRAGA, H. R.; ALMEIDA, M. C. Mudanças contábeis na lei societária: Lei $\mathrm{n}^{\circ} 11638$ de 28/12/2007. São Paulo: Atlas, 2008.

BRAGA, R.; MARQUES, J. A. V. C. Avaliação da liquidez das empresas através da análise da demonstração de fluxos de caixa. Revista Contabilidade e Finanças, v. 14, n. 25, p. 6-23, 2001 .

BRASIL. Lei $\mathrm{n}^{\circ} 11.638$ de 28 de dezembro de 2007. Diário oficial da união. Disponível em: <http://www.planalto.gov.br/ccivil_03/_ato2007-2010/2007/lei/111638.htm>. Acesso em: 05 abr. 2013.

Lei $n^{\circ} 11.941$ de 27 de maio de 2009. Receita Federal. Disponível em: < http://www.receita.fazenda.gov.br/Legislacao/leis/2009/lei11941.htm>. Acesso em: 05 abr. 2013.

Lei Complementar no 123 de 14 de dezembro de 2006. Receita Federal. Disponível em: <http://www.receita.fazenda.gov.br/Legislacao/LeisComplementares/2006/leicp123.ht>. Acesso em: 10 de maio 2013.

CONSELHO FEDERAL DE CONTABILIDADE. Resolução CFC nº 1.418 de 5 de dez. de 2012. APROVA A ITG 1000 - Modelo contábil para microempresa e empresa de pequeno porte. Disponível em:

<http://www.cfc.org.br/sisweb/sre/detalhes_sre.aspx?Codigo=2012/001418>. Acesso em: 5 abr. 2013.

BORGES, M. S. D.; NUNES, S. C. D.; ALVES, M. T. V. D. A demonstração dos fluxos de caixa e sua contribuição para uma tomada de decisão mais informada. Revista Universo Contábil, v. 8, n. 1, p. 141-158, 2012.

CAMPOS FILHO, A. Demonstração dos fluxos de caixa: uma ferramenta indispensável para administrar sua empresa. São Paulo: Atlas, 1999.

CLINCH, G.; SIDHU, B.; SIN, S. The usefulness of direct and indirect cash flow disclosures. Review of Accounting Studies, n. 7, n. 4, p. 383-404, 2002.

COMITÊ DE PRONUNCIAMENTOS CONTÁBEIS, Pronunciamento técnico CPC 03 (R2) Demonstração dos fluxos de caixa. 2010. Disponível em <http://www.cpc.org.br/mostraOrientacao.php?id=17> Acesso em: 05 abr. 2013. 
Pronunciamento técnico CPC 26 (R1) Apresentação das demonstrações contábeis. 2011. Disponível em <http://www.cpc.org.br/mostraOrientacao.php?id=45> Acesso em: 28 abr. 2013.

Pronunciamento técnico CPC PME (R1) Contabilidade para pequenas e médias empresas. 2009. Disponível em <http://www.cpc.org.br/mostraOrientacao.php?id=60> Acesso em: 05 abr. 2013.

FARSHADFAR, S.; MONEM, R. Further evidence on the usefulness of direct method cash flow components for forecasting future cash flows. The International Journal of Accounting, v. 48, p. 111-133, 2013.

FREZATTI, F. Gestão do fluxo de caixa diário: como dispor de um instrumento fundamental para o gerenciamento do negócio. São Paulo: Atlas, 1997.

GIL, A. C. Como elaborar projetos de pesquisa. 3. ed. São Paulo: Atlas, 1999.

GILIO, L.; AFONSO, L. E. Grau de aproximação entre a contabilidade gerencial e a contabilidade financeira em função de convergência às normas do IASB. Contabilidade, Gestão e Governança, v. 16, n. 3, p. 70-89, 2013.

GONÇALVES, M. A.; CONTI, I. S. Fluxo de caixa: ferramenta estratégica e base de apoio ao processo decisório nas micros e pequenas empresas. Revista de Ciências Gerenciais, v. 15, n. 21, p. 173-190, 2011.

IUDÍCIBUS, S.; MARTINS, E.; GELBECKE, E. R.; SANTOS, A. Manual de contabilidade societária: aplicável a todas as sociedades. São Paulo: Atlas, 2010.

JONES, S.; WIDJAJA, L. The decision relevance of cash-flow information: A note. ABACUS, v. 34, n. 2, p. 204-218, 1998.

KRISHNAN, G. V.; LARGAY, J. A., III. The predictive ability of direct cash flow information. Journal of Business Finance and Accounting, v. 27, n. 1-2, p. 215-245, 2000.

KWOK, H. The effect of cash flow statement format on lenders' decisions. The International Journal of Accounting, v. 37, p. 347-362, 2002.

LAKATOS, Eva Maria; MARCONI, Marina de Andrade. Metodologia científica. 6. ed. São Paulo: Atlas, 2011.

LEV, B.; LI, S.; SOUGIANNIS, T. The usefulness of accounting estimates for predicting cash flows and earnings. Review of Accounting Studies, v. 15, n. 4, p. 779-807, 2010.

MACEDO, M. A. S.; MACHADO, M. A. V.; MURCIA, F. D. R; MACHADO, M. R. Análise do impacto da substituição da DOAR pela DFC: um estudo sob a perspectiva do value-relevance. Revista Contabilidade e Finanças, v. 22, n. 57, p. 299-318, 2011.

MARION, J. C. Contabilidade básica. 10. ed. São Paulo: Atlas, 2009. 
MARTINS, E. Contabilidade vs. fluxo de caixa. Cadernos de Estudos FIPECAFI, n. 20, jan./abr. 1999.

MODRO, N. R. Sistema inteligente de monitoramento e gerenciamento financeiro para micro e pequenas empresas. Dissertação (Mestrado em Engenharia da Produção) Programa de Pós-Graduação em Engenharia de Produção da Universidade Federal de Santa Catarina, Florianópolis, 2000.

ORPURT, S. F.; ZANG, Y. Do direct cash flow disclosures help predict future operating cash flows and earnings? The Accounting Review, v. 84, n. 3, p. 893-935, 2009.

PADOVEZE, C. L. Contabilidade Gerencial: um enfoque em sistema de informação contábil. 7. ed. São Paulo: Atlas, 2010.

RAUPP, F. M.; BEUREN, I. M. Metodologia da pesquisa aplicável às ciências sociais. In: BEUREN, I. M. (Org.). Como elaborar trabalhos monográficos em contabilidade: teoria e prática. 3. ed. São Paulo: Atlas, 2004.

QUINTANA, A. C.; SAURIN, V. Análise da utilização da demonstração do fluxo de caixa como um instrumento de gestão financeira nas sociedades anônimas de capital aberto do estado do Rio Grande do Sul. Revista de Ciências da Administração, v. 10, n. 22, p. 55-79, 2008.

RICHARDSON, R. J.; Pesquisa social: métodos e técnicas. São Paulo: Atlas, 1989.

RIBEIRO, O. M. Demonstrações financeiras: mudanças na lei das sociedades por ações: como era e como ficou. 2 ed. São Paulo: Saraiva, 2010.

SERVIÇO BRASILEIRO DE APOIO AS MICRO E PEQUENAS EMPRESAS - SEBRAE. Disponível em: <http://www.sebrae.com.br/>. Acesso em: 25 de mai. 2013.

SILVA, E. C. Como administrar o fluxo de caixa das empresas. 5. ed. rev. São Paulo: Atlas, 2011.

TEIXEIRA FILHO, A. C.; MARQUES, J. A. V. C.; PAULA, M. M.; VIEIRA, S. S. C. Cumprimento das orientações normativas acerca da divulgação da demonstração do fluxo de caixa pelas companhias abertas que compõem o Ibovespa. Pensar Contábil, v. 13, n. 50, p. 14-22, 2011.

TOLEDO FILHO, J. R; OLIVEIRA, E. L.; SPESSATTO, G. Fluxo de caixa como instrumento de controle gerencial para a tomada de decisão: um estudo realizado em microempresas. Revista de Contabilidade do Mestrado de Ciências Contábeis da UERJ, v. 15, n. 2 , p. $75-88,2010$.

WALLACE, R. S. O.; CHOUDHURY, M. S. I.; ADHIKARIZ, A. The comprehensiveness of cash flow reporting in the United Kingdom: some characteristics and firm-specific determinants. The International Journal of Accounting, v. 34, n. 3, p. 311-347, 1999.

ZDANOWICZ, J. E. Finanças aplicadas para empresas de sucesso. São Paulo: Atlas, 2012. R. Cont. Ufba, Salvador-Ba, v. 9, n. 1, p. 93 - 112, jan-mar 2015 